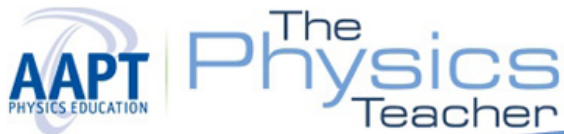

\section{An example of motion in a course of physics for agriculture}

Ivan Amaral Guerrini

Citation: The Physics Teacher 22, 102 (1984); doi: 10.1119/1.2341479

View online: http://dx.doi.org/10.1119/1.2341479

View Table of Contents: http://scitation.aip.org/content/aapt/journal/tpt/22/2?ver=pdfcov

Published by the American Association of Physics Teachers

\section{AAPT Re-register for Table of Content Alerts}




\title{
An example of motion in o course of physics for agriculture
}

\author{
Ivan Amaral Guerrini \\ Departàmento de Biofísica, Instituto Básico de Biologia Medica e Agricola \\ Universidade Estadual Paulista, 18610 Botucatu, SP, Brazil
}

Agronomy students, beginning to attend physics classes, usually demand examples of physical applications in their future activities in order to accept the idea of the importance of physics for them. As professors and educators that is also our objective.

So, with respect to the study of motion within the chapter on dynamics, students are introduced first to a review of uniform motion, and, then, to motion with constant acceleration: free fall, for example. At this time they are also taught the construction and interpretation of linear and logarithmic graphs. After that they are ready to be presented to a new and interesting example of movement: the horizontal infiltration of water in soil.

That kind of movement (although the correct analysis would demand a rigorous mathematical treatment of the flow of water in porous media) can be studied as a power function model given by the following equation:

$$
x=k t^{\alpha}
$$

where $x$ is the position coordinate of the wetting front movement, $t$ is the time coordinate, and $k$ and $\alpha$ are the positive parameters to be determined, $\alpha$ being the one that defines the specific motion. The first step to identify the motion is to plot $x$ versus $t$ in a linear graph. The three possible cases are shown in Fig. 1.

Case II is the simplest, because it is the only one for which $\alpha$ can be determined by inspection. It's important to show the students that Case II is just a particular one, nevertheless very important in physics, where the velocity is constant and acceleration is zero. In the other two cases, it's necessary to linearize the equation using logarithms, which yields:

$$
\log x=\log k+\alpha \log t
$$

A $\log -\log$ graph of $x$ versus $t$ gives a straight line and it is easy to find $\alpha$ and $k$ from the slope and intercept.

At this point the students are given the experimental equipment to be utilized, and then samples of two soils, labeled $A$ and $B$. These are contained in acrylic columns of $5.6 \mathrm{~cm}$ internal diameter as shown in Fig. 2. Experimental data obtained with those soil samples are given in Table I, where the time intervals were chosen in order to maintain the equidistance of the points in the log-log graph.

The experimental data of Table I initially plotted on a linear graph yields a power curve similar to Case III of Fig. 1, where $\alpha$ is less than unity, which indicates the existence of an acting force diminishing with time. It is explained to the students that the origin of that force is the capillary forces between water and soil particles, one of the main phenomena occurring with soil water.

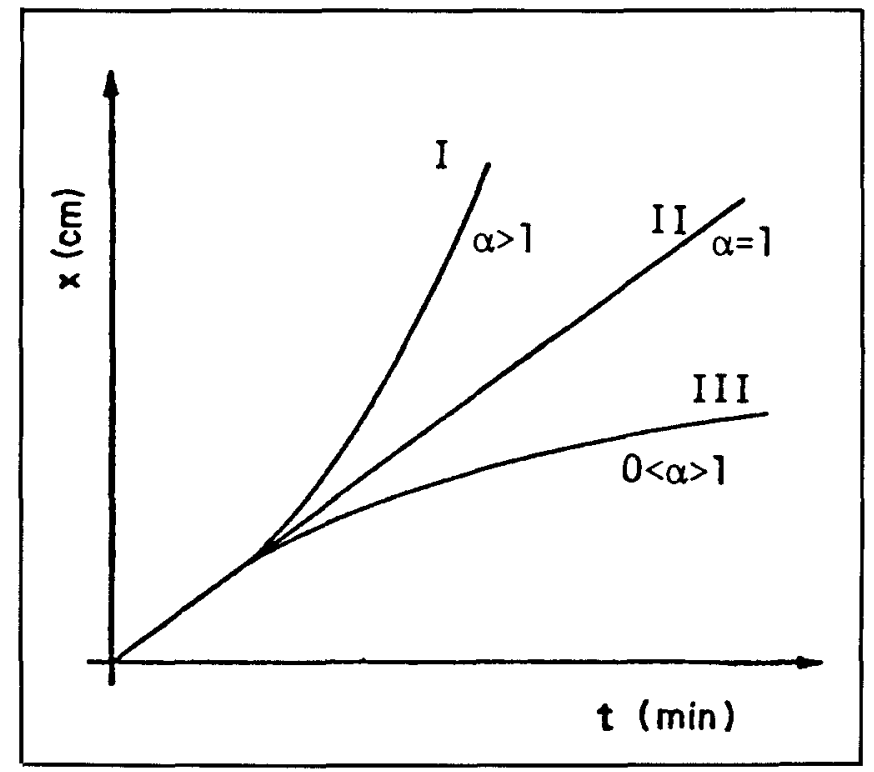

Fig. 1. Plot of equation $x=k \cdot{ }^{\alpha} \alpha$ for the three possible cases.

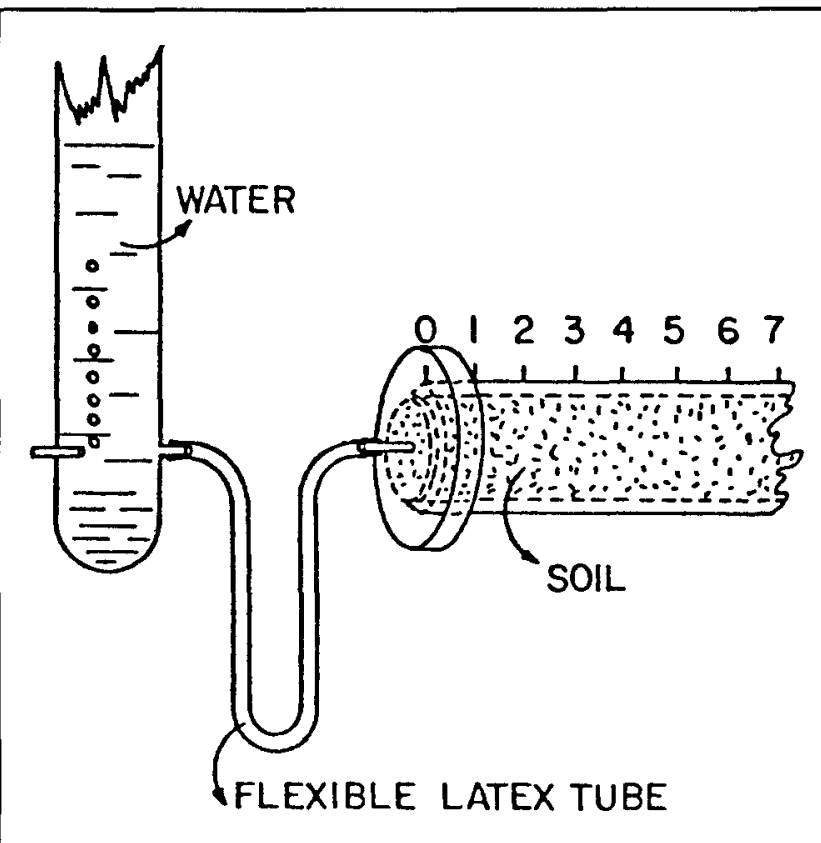

Fig. 2. Experimental equipment utilized. 


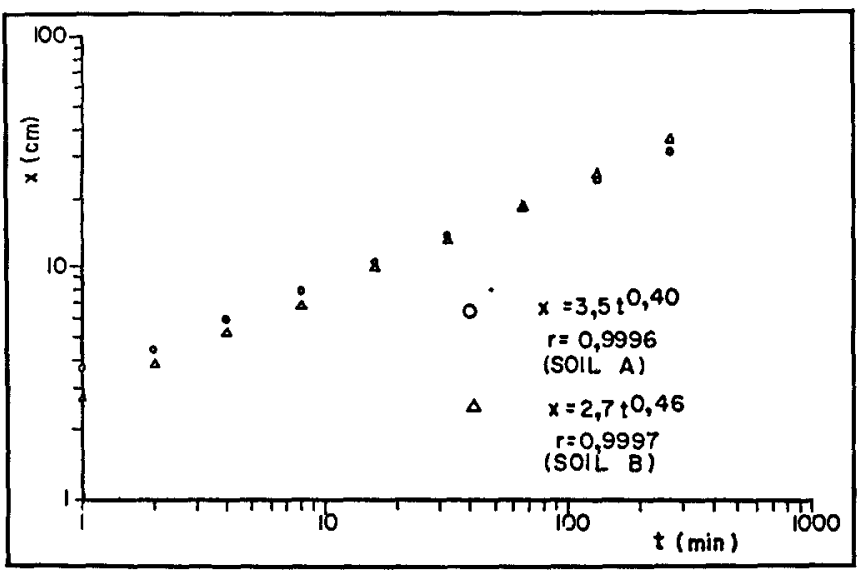

Fig. 3. Log plot of Table I data, where $r$ is the linear correlation coefficient.

\begin{tabular}{|ccc|}
\hline \multicolumn{3}{|c|}{ Table I } \\
Experimental data of wetting front movement \\
$\mathrm{t}$ & \multicolumn{2}{c|}{$\times(\mathrm{cm})$} \\
\cline { 2 - 3 }$(\mathrm{min})$ & Soil A & Soil B \\
1 & 3.7 & 2.7 \\
2 & 4.5 & 3.8 \\
4 & 6.0 & 5.2 \\
8 & 8.0 & 6.9 \\
16 & 10.6 & 9.9 \\
32 & 13.8 & 13.2 \\
64 & 18.6 & 18.4 \\
128 & 24.3 & 25.7 \\
256 & 32.0 & 36.1 \\
\end{tabular}

The Table I data plotted logarithmically in Fig. 3 show good straight lines for both soils as is confirmed by the linear correlation coefficients, which are related with the linearization of the data.

Once the parameters $k$ and $\alpha$ are obtained, giving the power equations for soils $A$ and $B$, which are written in Fig. 3, the students are asked to derive velocity and acceleration definitions to complete the equations related to the movement studied. This procedure gives:

$$
\begin{array}{ll}
x=3.5 t^{0.40} & \text { b) Soil B } \\
\mathrm{v}=\frac{d x}{d t}=1.4 t^{-0.60} & \mathrm{v}=\frac{d x}{d t}=1.2 t^{-0.54} \\
a=\frac{d \mathrm{v}}{d t}=-0.84 t^{-1.60} & a=\frac{d \mathrm{v}}{d t}=-0.67 t^{-1.54}
\end{array}
$$

These results show the students that the acceleration, and so the force acting on the soil water has a negative power variation with time, making it a special, but simple, kind of movement.

\title{
Physics in a bouncing car
}

\author{
Albert A. Bartlett \\ Department of Physics, University of Colorado, Boulder, Colorado 80309
}

Here are two interesting variations of a problem that can be given to students to encourage them to think about very common observations in everyday mechanics.

Objects in free-fall all have the same acceleration ( $\sim 9.8 \mathrm{~m} / \mathrm{s}^{2}$ ), so a freely falling car can't have a greater downward acceleration than a falling person. How then is it possible that a person riding in a car can bump his/her head on the roof of the car when the car goes up over a severe bump?

One hopes that the students will recognize that as the car accelerates upward in passing over a bump there is an extra compression of the springs in the seat cushions on which the person is sitting. A part of the energy of the upward motion of the car is converted to potential energy of the form $\left[(1 / 2) k x^{2}\right]$ of the compressed seat springs. This potential energy is then used to "launch" the passenger upward and to help accelerate the car downward.
Because of the time taken to compress the seat springs, the maximum upward acceleration of the passenger occurs a short time after the maximum upward acceleration of the car. Thus the head of the passenger going upward may meet the roof of the car going downward in a painful inelastic collision.

This interaction of the car body, the seat springs and the passenger could be viewed from a reference frame that is rigidly attached to the car body. ${ }^{1}$ As the car body accelerates upward with an acceleration $a$, the weights of objects increase when measured with respect to the car body

$$
W^{\prime}=m(g-a)
$$

where $g=-9.8 \mathrm{~m} / \mathrm{s}^{2}$ and $a$ is positive when it is upward. ${ }^{2}$ Then later as the car body accelerates downward the weights of objects decrease when measured with respect to 